\title{
Continuum
}

Journal of Media \& Cultural Studies

\section{Before the consummation what? On the role of the semiotic economy of seduction}

\section{George Rossolatos}

To cite this article: George Rossolatos (2016): Before the consummation what? On the role of the semiotic economy of seduction, Continuum

To link to this article: http://dx.doi.org/10.1080/10304312.2016.1141866

曲 Published online: 18 Feb 2016.

Submit your article to this journal $๘$

Q View related articles $\asymp$

View Crossmark data \lceil 


\title{
Before the consummation what? On the role of the semiotic economy of seduction
}

\author{
George Rossolatos \\ Department of English, University of Kassel, Kassel, Germany
}

\begin{abstract}
The cultural practice of flirtation has been multifariously scrutinized in various disciplines including sociology, psychology, psychoanalysis and literary studies. This paper frames the field of flirtation in Bourdieuian terms, while focusing narrowly on the semiotic economy that is defining of this cultural field. Moreover, seduction, as a uniquely varied form of discourse that is responsible for producing the cultural field of flirtation, is posited as the missing link for understanding why flirtation may be a peculiar case of non-habitus, contrary to the received notion of cultural field as set of goaloriented practices and actionable habituses. This argument is pursued by highlighting the endemic traits of ambivalence and constant reversibility of signs or multimodal semiotic constellations in the discourse of seduction, while seeking to demonstrate that seduction, and by implication the cultural field of flirtation, does not necessarily partake of a teleological framework that is geared towards the consummation of sexual desire. This thesis is illustrated by recourse to a scene from the blockbuster 'Hitch'.
\end{abstract}

\section{ARTICLE HISTORY}

Received 21 March 2015

Accepted 17 December 2015

\section{KEYWORDS}

Habitus; cultural field; semiotics; flirtation; seduction; semiotics

\section{Introduction}

The discourse of flirtation and flirting as cultural practice is an instrumental aspect of natural and cultural reproduction. Simmel, in his early twentieth century-pioneering sociological exploration of the structure of flirtation, exalted its mysterious workings, while stressing that the social form of flirtation'achieves its most typical and purest fulfillment [...] in the relationship that conceals within itself perhaps the most mysterious and tragic relation of life in its ultimate ecstasy and most glittering attraction' (Simmel 1984, 152). The social practice or, in Bourdieuian terms, cultural field of flirtation has been theorized (Tavory 2010) as a series of 'suspended interactions' that leave different unfoldings of a situation open, while being characterized by sudden shifts in interactional frames (in Goffman's sense of the term 'frame').

The notion that we live in a flirtatious culture is highly evocative in a postmodern age and works well as a metaphor

for the fluid, transitory nature of experience in the late 20th and early 21st centuries (Yates 2010,5)

The consolidation of this cultural predicament was facilitated by the advent of the Internet which spawned e-variants of time-hallowed, 'bricks'n'mortar' flirting methods, such as cyber-flirting (Whitty 2004) and m-flirting (mobile flirting; see Williams 2013). 
Flirting may be defined, from an instrumentalist/telic point of view, as a seductive discourse that is geared towards the fulfilment of sexual desire (and has been thus framed by Simmel [1984]) or as 'playful behavior intended to arouse sexual interest )' (Tavory 2010, 63). Sexual desire, in turn, may be further viewed either as temporary consummation of a biological need or inscribed within the horizon of reproductive, agapetic love. Either way, flirting usually constitutes an intermediary stage or a processual aspect of the pathway to desire's consummation. As such, it has been variably theorized in various disciplines, including sociology, philosophy, psychoanalysis and, more peripherally, semiotics. This paper draws primarily on Bourdieu's sociological theory and more specifically on the interlocking concepts of habitus, field and capital in order to delineate the cultural field of flirting as a ubiquitous social practice and dominant narrative structure in popular cultural artefacts, such as movies (cf. Section 2.1 - the case of 'Hitch'), that will be evoked while illustrating my argumentation. However, insofar as seduction as strategic/tactical communicative toolbox constitutes an indispensable facet of the cultural field of flirting, I am also drawing on Baudrillard's semiotic insights and relevant literature from philosophy and sociology with an intent on canvassing the morphology of signs of seduction in the cultural field of flirting.

The argumentative thrust that is deployed in this paper seeks to demonstrate that the seductive 'discourse' that is integral to the practice of flirting constitutes a peculiar case that only partly may be said to abide by the instrumental reasoning orientation and goal-oriented activities that are essential components, according to Bourdieu, of cultural fields (cf. Swartz 1997, 99; 'Bourdieu considers all action to be interest-oriented'). Despite the spreading biopower ethotic pattern that seeks to colonize and systematize the farthest corners of random human interaction, as may be attested by the increasing popularity of professional dating services that are concerned with the obscenely (according to Baudrillard's [1990] axiology) microscopic engineering of flirtatious interaction patterns and their subjugation to an investment rationale of calculable risk, the inherently resistant nature of seductive tactics to their sublation by a hegemonic discourse is indicative of a unique cultural predicament, where the means constantly undercut the materialization of the field's telos (for Bourdieu practice is 'informed by a kind of objective finality'; Fowler 1997, 19). This is what I call the double movement of seduction, that is a fuzzy set of communicative regularities (and far from systematizable rules of interaction) that constantly postpone, suspend and mitigate the probability of attainment of the goal of sexual fulfilment inasmuch as they appear to be working towards the materialization of desire's telos.

The law of seduction takes the form of an uninterrupted ritual exchange where seducer and seduced constantly raise the stakes in a game that never ends [...] Sex, on the other hand, has a quick, banal end: the orgasm, the immediate form of desire's realization. (Baudrillard 1990, 22)

And in any case, seduction stands 'in ironic contrast to orthodox relationship formation' (Deighton and Grayson 1995, 669).

\subsection{The non-erotic aspect of seduction}

It is a common place that when we ascribe the predicate 'seductive' to something or someone, we imply 'erotic' or desirable by virtue of erotic appeal. Seduction and seductive have been amply operationalized in this manner in sociological studies. For example, Vannini and McRight (2004) attribute seductive status to bodies by virtue of their partaking of a political (libidinal) economy of bodies where the value of the sign 'tanned body' is customarily exchanged for 'eroticism.' However, as I will argue in this paper, in line with Baudrillard's 'theses' (or, rather, speculative doxic positings) as propounded in Seduction (1990), seduction is far more than a mere synonym for 'erotic.' 'Seduction is stronger [...] than sexuality, with which it must never be confused. It is not something internal to sexuality, though this is what it is generally reduced to' (Baudrillard 1990, 47). Seduction may be viewed as a tactical communicative toolbox; arguably, but less cogently so, as a communicative strategy; and as the gateway to the attainment (fulfilment) or consummation of sexual desire. At the same time, seduction's radical ambivalence, undecidability and constant reversibility (as regards the outcome of a seductive communicative 
process) - integral traits of the flirtation field, as noted by Simmel (1984) - constitute an attestation of its non-teleological character, and hence corroborative not only of its being non-synonymous to the 'erotic', but not even subsumable under sexual desire as precursory stage towards its consummation. This is a fundamental position assumed by Baudrillard throughout Seduction (1990) with which I tend to align (although not being in agreement with Baudrillard's entire spectrum of assertions concerning the function of seduction vis-à-vis chance, the political, the erotic and a whole host of other socio-political dimensions whereby seduction is put in perspective). In short, seduction as a communicative process functions for and against the erotic, but, at least, it is by no means reducible to it.

\subsection{The non-habitus of seduction}

My contention is that the seductive discourse of flirting is a radical case of non-habitus. In order to elucidate this perhaps impossible thesis, let me expose in brief the meaning of habitus, according to Bourdieu, as the concept is necessarily coupled with those of cultural field and various forms of capital (cultural, social, linguistic and economic) ${ }^{2}$ with which I shall be concerned in the following section.

An agent's habitus is an active residue or sediment of his past that functions within his present, shaping his perception, thought, and action and thereby molding social practice in a regular way. It consists in dispositions, schemas, forms of know-how and competence, all of which function below the threshold of consciousness [...] In this respect habituses are 'structured structures'. Or rather, they are structured structuring structures. (Crossley 2001, 83-84; Fowler 1997, 18)

Given Bourdieu's anti-structuralist posture, at least in the context of his received conception of structuralism that was largely informed by Saussure and Levi-Strauss (rather than contemporaries, such as Greimas), habituses as enabling structures are conceived as patterned regularities, rather than binarist abstractions in the form of meta-theoretical rules of epistemic status. Habituses as patterned regularities versus rule-bound behaviours are a crucial distinction that allow us to appreciate Bourdieu's uniquely praxiologically oriented sociological theorizing that explicitly seeks to part ways with any behaviourist (or, more contemporarily aptly, 'experimentally psychological') imposition on social action as conditioned stimulus-response patterns, and, moreover, as a transformation of this conditioning (albeit in bad faith) into'conscious responses' that have their seat in individual free will:'The habitus of the dominated frequently leads them to choose actively what they are objectively constrained to do' (Fowler 1997, 18).

Habitus is quasi-deterministically conditioning as a result of a social actor's learnt response patterns while immersing oneself in language games, an ongoing learning process that allows for improvisations on recurrent patterns of social interaction. 'Actors who are proximate in social space have (more) similar habitus because they are more likely to be interacting with one another, mutually influencing one another and therefore mutually shaping their respective habitus' (Bottero and Crossley 2011, 102). In this context, one's habitus is equivalent to a set of semiotic constraints according to identifiable cultural fields, as will be further elaborated in due course. Semiotic constraints concern the scope of meanings that may be attributed to constellations of signs in discrete cultural fields or relationships between signifiers and signifieds.

Disposition is a central definitional component of habitus. In the context of seduction as process, as we are informed by Baudrillard (1990), the only a priori certain disposition is 'vertigo', that is the incidence of 'shock' in the face of the inherent reversibility of signs. Reversibility, then, is an a priori scheme of seduction's habitus that is causally related to the background expectancy of vertigo. This constant threat of reversal in the context of flirtation has been noted by Simmel, ever since the turn of the twentieth century:

There is a sense in which flirtation lends a positive concreteness to not-having, making it tangible for the first time by means of the playful, suggestive illusion of having, just as, conversely, flirtation intensifies the attraction of having to the most extreme degree by means of the threatening illusion of not-having. (Simmel 1984, 150)

What, then, appears to be the case for seduction is the incidence of two conditionals, of dispositional and schematic forms, respectively, viz., those of vertigo and reversibility of signs. Insofar as both conditionals are negative, as the former constitutes an expectation without determinate content or a pre-reflective 
response pattern not to a stimulus, but to the radical indeterminacy and uncertainty of the meaning of stimuli, and the latter a fundamental negation of signs' signification, we may infer that the habitus of seduction is, in fact, a non-habitus or a negative habitus. This anti-habitus only informs social actors who engage in a seductive communicative process about the impossibility of expecting a determinate result from their engagement in the play of seduction.

If habitus, in principle, according to the received and customary meaning attributed by Bourdieu, is both constraining (e.g. by reducing the probability of social mobility) and enabling (e.g. by equipping social actors with orientation strategies for navigating the social milieu of cultural fields), the habitus of seduction is 'ensnaring': 'The seductress turns desire itself into an illusion or trap' (Baudrillard 1990, 85). A remarkable example of the superiority of seduction, its ephemeral rules and its menacing force vis-a-vis the law is offered in the movie Basic Instinct. ${ }^{3}$ Sharon Stone's exemplary enactment of the seductress role in this movie consists in playing at being the object of a detective's (Michael Douglas) desire only to entrap him in her seductive game and hence affirm her ultimate purpose as annihilation of desire (or substitution of sex with death, thus turning sex as metonymically rendered 'petit mort' into literal death, while attesting to the over determination of the eros by the death drive). Michael Douglas is lured to (almost) death in order to discover the secret truth that slides constantly beneath the signs of the professional seductress (Stone). Douglas is driven by desire in his quest, whereas Stone is driven by the play itself that annuls desire. The meaning of the discrete moments of seduction is constantly postponed until the final scene where Douglas is not killed, save for portraying Stone's intention to kill, as the message is addressed to the audience, viz. if there is an apocalypse to the endless play of seduction, then it may be known only at the price of death. Or, there is no truth in seduction, and if there is one, this is equivalent to seduction's annulment. Seduction is a game of infinite postponement and annihilation of any epiphany that might radiate through the surface of the text. Furthermore, in seductive communication, players' know-how is constantly challenged by uncontrollable factors, and hence competence is reducible to incompetence. The only'objectively relevant', in Bourdieu's terms, condition as culturally engraved expectancy in the context of seduction is a relationship with the negative.

In the light of these bespoke conditionals that pertain to the practice of flirting, we are forced to reconsider the function of habitus, as mediating between structure and practice (Mander 1987, 428), and reformulate it as unstructured unstructuring unstructures or the inscription of improbable structures in the process of attempting to impose structure or reverse the irreversibility of inherently reversible structures. Seductive communication is like a game of dice insofar as regardless of whether a century's worth of time series data might suggest that the probability of yielding six times six in a row is 0 , nothing prevents, in principle, actually yielding six times six in the next throw. This is why seductive communication is of anti-betting disposition, as one does not bet against odds, but against pure chance or the improbable. The only objectively relevant and binding condition for this habitus, then, is the expectancy of the improbable as anyhow reversal.

This expectancy may also be likened, in psychoanalytic terms, ${ }^{4}$ as a radical logic of castration in the face of the absence of any visibly signifying signs that might effect a resolution to the uncertainties that beset a productive (phallic) economy (also see Rossolatos 2015). Due to the signs' constant reversibility, none of the actors who engage in a seductive play is powerful or in possession of the phallus, while both are conditioned by the constant sliding of the negative beneath the surface play of signifiers (linguistic or multimodal) that emerge quasi-regularly in thematically shifting turn-taking.

\section{The seductive production of the cultural field of flirtation}

In the context of Bourdieu's mature theory of practice, the habitus concept functions in conjunction with (at least) two further key concepts, capital and field [...] What is added by the concepts of field and capital is an account of the context of action, the resources available to the actor within that context, and the respective role these factors play in the shaping of the action. (Crossley 2001, 86)

By 'field' we refer to a distinctive social microcosm that carries its own characteristic practices, rules, forms of authority and standards of evaluation '(Fantasia 2010, 28; Martin 2003; Swartz 1997). 
Societies comprise interlocking fields that may be further distinguished into institutional and noninstitutional. Non-institutional fields are akin to social practices that are deployed against tacit rules, that is rules that are implicitly recognized and enacted by social actors while engaging in such practices, yet whose status has not been explicitly formulated and recorded in an institutional vein. Hence, fields as social practices are more akin to 'games', as language games, in Wittgenstein's sense. Engagement in a game is of pre-reflective nature, a dialectic between milieu and action, mediated by a set of gaming competencies as 'feel for the game'. Sports analogies abound in the exemplification of cultural fields and game-related competencies as 'feel for the game': 'The cornerstone of the theory is the two-way relationship between objective structures of social fields ("the game itself") and the incorporated structures of the habitus ("the feel for the game")' (Savage and Silva 2013, 113). The 'feel for the game' is akin to a pre-reflective understanding or, as put by Taylor (1999, 34), 'inarticulate understanding' that guides our practical engagement with the world, antedates and helps shape representations.

In the case of the social game, where regularity without the rules is very much (so to speak) the rule rather than the exception, it is tempting to tell oneself that it is perhaps vain to try and go beyond notions like that of a practical sense or feel for the game. (Bouveresse 1999, 52)

The sports analogy, though, is contestable since most sports are bound by explicit game rules where actions, sanctions and violations are prescribed and often institutionalized, unlike informal cultural fields, such as flirting. For example, in football, there is a world cup institution, a formal FIFA organization, a specific field where the game is played (i.e. football field) with explicitly demarcated spaces. On the contrary, there is no institutional body for the social practice (cultural field) of flirting or explicitly prescribed social spaces where it may be enacted. The less institutionalized the field, the greater the role of chance in determining the attainment of the goal that is involved in engaging with the cultural practice it circumscribes, but also the less formalizable the requisite competencies and the less calculable the result. This is why technologies of self, such as those provided by professional dating services, for example, are paramount in streamlining the habitus or the ethotic patterns that unite individuals in distinctive and identifiable habituses, like rules of etiquette that are bequeathed from group member to group member, yet which are not prescribed in manuals (although they may be reflected in ethnographic, e.g. accounts, scholarly monographs and popular press articles).

Bourdieu's field theory has been extensively and intensively applied for analysing, categorizing and mapping out as variegated sociocultural phenomena as emerging music genres (Beer 2013), the formation of collective taste in an erotic arts club (Wohl 2014), the hip hop culture (Elafros 2012), the shifting landscape of French gastronomic practices (Fantasia 2010), the internationalization of business elite networks (Bühlmann, David, and Mach 2013), the emergence and networked structure of the punk scene in the UK (Bottero and Crossley 2011) and the shifting taste dynamics of the comedy genre (Friedman and Kuipers 2013). Nevertheless, the notion of field is not bereft of substantial criticisms, such as the 'fuzziness' of fields' borders, especially given Bourdieu's assertion that the demarcation of a field should, optimally, take place against all other fields in a social milieu or, at least, of those directly adjacent to it. 'Indeed, the problem of "fuzzy" borders in fields is a long acknowledged problem that Bourdieu himself identified' (Beer 2013, 150). Moreover, the notion of cultural field appears to be a highly ambivalent umbrella concept with multiple definitions and unclear conceptual boundaries. Savage and Silva $(2013,115)$ suggest that this slippage of definitions is part of Bourdieu's strategy of using concepts as tool-kits in empirical research, while identifying (Savage and Silva 2013, 116) four dominant ways whereby field is employed by Bourdieu in order to fulfil occasionally contradictory purposes: (i) fields present themselves synchronically as structured spaces of positions; (ii) from a phenomenological point of view, as the way that the concept brings out the importance of the 'feel for the game' which embodies Bourdieu's commitment to the practical sense; (iii) in a manner akin to Lewin's force-fields, as developed in gestalt philosophy, and in the natural science of gravitational and electrical forces; and (iv) by focusing in Weberian style on the competitive aspect of field relations. 
If individuals occupy the same "social space" for Bourdieu this is not in virtue of their social relationships with each other but because they share similar structural relations to economic and cultural resources' (Bottero and Crossley 2011, 101) in various cultural fields. Although Bourdieu did not outline explicitly a process for mapping out fields, Grenfell $(2010,21)$ suggested a three-stage process based on Bourdieu's prolific applications in separate works. At the first level, the relationships between the field and other fields - in particular, the field of power - are established. At the second level, the field itself is 'mapped' in terms of morphology, taxonomy, the positions occupied by the involved social actors and the forms of capital that pertain to the field. At the third level, interacting cultural field actors are analysed in terms of their habitus, that is socio-economic background, trajectory and positioning in relation to the field under study. Amidst this all-encompassing blueprint in this paper, I am primarily concerned with the second level and particularly with mapping out the morphology of signs of seduction in the cultural field of flirting and with the field's forms of capital.

The explicit stress on the semiotic economy that circumscribes seduction as tactical toolbox available to social actors who interact in the cultural field of flirting may afford to elucidate the modus operandi of this peculiar field which seems to be transgressing the majority of conditionals that have been posited by Bourdieu for understanding and mapping habituses, cultural fields and forms of capital. In order to render this modus operandi concrete, I will try and demonstrate that the exchange of signs of seduction among flirting subjects is even more 'magical' (an attribute with which signs of seduction are invested by Baudrillard [1990]) than what Butler (1999) christens the 'magic of the performative' in her demonstration of the intertwinement between habitus and discursivity. Butler (1999) contends that performative utterances whose illocutionary force is responsible for bringing about 'magically' the intended communicative outcomes (e.g. the oft quoted employment of the declarative utterance 'I do' in a marriage setting) are also responsible for the discursive constitution of subjectivities and for their 'objective' habituation in distinctive cultural fields. 'The interpellation as performative establishes the discursive constitution of the subject as inextricable from the social constitution of the subject' (Butler 1999, 120). Linguistic utterances, according to Butler (1999), are the outcome of subjects' 'linguistic habitus'. By extension, linguistic utterances also give rise to 'linguistic capital' as a special sub-class of cultural capital. However, given that, as stressed by Taylor (1999), the habitus is largely pre-reflective and pre-articulative and, hence, pre-linguistic; a further elaboration of cultural capital into 'semiotic capital' would be more apt in encapsulating the disposition of subjects to interact in a given field and their employed signs and tactics. Insofar as the playful and seductive process that paves the way to the attainment of symbolic capital is strewn with ephemerally correlated signifiers with signifieds, under which the archi-signified of consummation constantly slides, the competencies and strategic orientation dispositions with which interacting social actors in the concerned cultural field must be equipped are of a semiotic order and, hence, aspects of their semiotic capital. This opening up of linguistic habitus and capital becomes even more compelling once we come to realize that the pre-linguistic character of the habitus does not entail necessarily its pre-semiotic status. Yet, the habitus is a marked attestation of the pre-semiotic constitution of subjectivity, as plenum of orientation markers that condition strategically a subject's comportment in practical situations in the wider project of engaging with the world. This is further compounded by the particularities of the cultural field of flirting and seductive communication as its essential adjunct where due to the postponement and reversibility of signs' signification, we cannot lay claim to any sort of discursive constitution of the involved subjects, if not of their discursive dissipation. What we are left with is a failure of discourse and the liquidation of linguistic capital. In Baudrillard's words,

all meaningful discourse seeks to end appearances: this is its attraction, and its imposture. It is also an impossible undertaking. Inexorably, discourse is left to its appearances, and thus to the stakes of seduction, thus to its own failure as discourse. (Baudrillard 1990, 54)

'Every discourse is threatened with this sudden reversibility, absorbed into its own signs without a trace of meaning' (Baudrillard 1990, 2). 
The variable modes whereby orientation markers are evinced in a subject's ordinary comportments (e.g. haptic, sonic and visual), and their corporeal embeddedness, as against their intellectualist confinement within a linguistic territory that is in marked contrast to Bourdieu's wider anti-intellectualist (see Bourdieu 1985, 723), but also anti-dualist (Swartz 2003) posture, attest to the importance of scrutinizing the pre-formative, strategically orientating and enabling (but at the same time constraining) nature of the habitus in terms of a semiotic economy as a set of orientation markers for navigating a cultural field or social space, while positing that these markers constitute at the same time the semiotic constraints that demarcate a cultural field. Moreover, insofar as a cultural practice that is situated in a cultural field and that abides by a certain practical logic is not fully accountable by recourse to a string of performative or illocutionary utterances (which are identified by Bourdieu [1991, 109] with 'surplus of meaning'), but involves all sorts of multimodal components, from one's disposition for moving in a specific manner in a given social milieu to handshaking in a specific manner to displaying all sorts of muscular facial contractions while engaging in conversational turn-taking with peers in an urban space, we can hardly constrain the production of the social within the boundaries of linguistic performativity. This does not preclude, however, tentatively opening up performativity to multimodal aspects, without assuming that the potentially infinite micro-constellations of interacting modes in bringing about the social may be accounted for by a set of combinations as explicit encounter rules (which, somehow, mitigate the interpretive cogency of performative theory in general). The preponderance of the non-performative generativism of the semiotic over the 'magical' bringing-froth of the social through the linguistically performative may be further demonstrated by allusion to the habitus as a generative principle of regularities, rather than rules. In order for a performative utterance to work, it must hold a rule-like status, in the form of 'if $X$ then (by necessity) $Y$ ', whereas in the case of regularities, we are concerned with (non-calculi) of the form 'if $X$ then (perhaps, more or less likely) $Y$ '. The problem is that $X$ in the former case is resolved in linguistic utterances, whereas in the latter, we are concerned with uncontrollably ramifying interactions among modes.

This crucial difference may be further elaborated by comparing between the illocutionary force of a promise uttered by a father to a son in their home garden and a multimodal semiotic constellation (say an eyebrow movement coupled with licking a straw that is placed in a glass of liquor) that is written on the corporeal surface (given that we are concerned with writings in the flesh) of a female subject while interacting with a male subject in a bar. In the father/son scenario, the very utterance of the promise bona fide brings forth the anticipated result, that is the production of the content of the utterance (e.g. the purchase of a new computer game). The utterance institutes a pact and rightly so because it is mutually expected in the father/son habitus that a father's promise is institutive of a pact. However, in the case of the female/male flirting predicament, the eyebrow/licking multimodal constellation constitutes a performatively uncertain step in an interactional stream of a cultural practice which neither depends on antecedents nor is necessarily anticipating the advent of a specific result. As rightly pointed out by one of the anonymous reviewers of this paper, both speech-acts may be viewed as commissives, based on Austin's classification of speech-acts into verdictive, expositive, exercitive, behabitive and commissive. In this case, the decision as to which speech-act type each of the concerned illocutionary acts belongs is incumbent on examining them against a set of distinguishing criteria, such as those proposed by Searle (1979), that is differences in the direction of fit between words and world, in the strength with which the illocutionary force is presented, in relations to the rest of the discourse, etc.

Not only a flirtatious multimodal constellation at time $X$ in the temporal deployment of a recognized practice as part and parcel of an objectively common habitus is not coupled per se with a specific performative outcome, but, on the contrary, it is indicative of the outcome's postponement until further 'semiotic notice'.

What binds the subjects in the father/son predicament is a behavioural rule that prescribes the advent of a specific outcome for the performative utterance, whereas what binds the subjects in the flirting predicament is the absence of a prescribed outcome as postponement of the meaning of a semiotic multimodal constellation that is inscribed in the flesh in the context of an ongoing interaction that is edified on the seductive overlap between multimodal signs that partake of quasi-prescribed 
regularities. 'And this nothing/secret, this, the seduction's un-signified moves beneath the words and their meaning, and moves faster than their meaning [...] A seduction beneath discourse, an invisible seduction, moving from sign to sign - a secret circulation' (Baudrillard 1990, 80). The postponement that is afforded by the inherent undecideability of the meaning of the multimodal constellation at point $X$ in the deployment of a non-deterministically prescribed and quasi-regularity bound interaction between the social actors points to no single certainty. It is precisely the power of the part, the sequence, to postpone or irreparably reverse the eventuality of the sequence that legimitates us in claiming that the postponement of the advent of the sequence's meaning is tantamount to the undercutting of the instrumentality of the multimodal inscription and its necessary subsumption in the latent teleology of the field in which it is embedded and which guides tacitly its use. By virtue of the undercutting of the field's telos, we are no longer situated in the territory of practical reason, or, at least, not only within practical reason, but within the territory of seduction and the seductive employment (that is noninstrumental) of multimodal constellations. The inscription of this constellation in the telic (teleological) framework of a cultural field does not fully account for the non-teleological postponement that is afforded by the employment of seductive semiotic constellations. This is a paradoxical situation insofar as the latent telos that channels or steers the deployment of its moments is constantly undercut by the very 'logic' that strings these moments, that is the logic of seduction or the radical uncertainty of the materialization of the field's telos: It is never an economy of sex or speech, but an escalation of violence and grace, an instantaneous passion that can result in sex, but which can just as easily exhaust itself in the process of defiance and death' (Baudrillard 1990, 81).

\subsection{The case of 'Hitch' or on the radical uncertainty and postponement that underpin multimodal constellations in the cultural field of flirtation}

In order to illustrate the radical uncertainty and constant postponement of the signification of multimodal constellations in the process of flirtation, I shall now analyse a scene from the blockbuster Hitch (2005), starring Will Smith and Eva Mendez. The movie revolves around the earlier mentioned thematic of technologies of self and the emergence of professional dating services, but also the dynamic between flirtation as auto-telic field and as teleologically driven by the cultural exigencies for procreation. Will Smith performs the character of a professional flirting instructor who teaches not particularly competent students the secrets of the 'art of courtship.' He is a professional seducer or seduction's worst enemy by dint of impersonating the archetype of the strategist who, by definition, seeks to counter the principles of reversibility, uncertainty and postponement that are definitive of the practice of flirtation. Eva Mendez plays a gossip columnist at a newspaper called Standard, and, as may be gleaned from the below transcribed scene (Table 1$){ }^{5}$ she is in principle aversive to play for the sake of play, while manifesting a proclivity for stable relationships at the expense of one-night stands or ephemeral adventures. The

Table 1. Modes employed in the analysis of the 'Hitch' scene and their hierarchical ordering.

\begin{tabular}{lcc}
\hline Mode & Acronym & $\begin{array}{c}\text { Ordering } \% \text { of incidence in the total } \\
\text { of } N=72 \text { modal incidences) }\end{array}$ \\
\hline Facial expression & $(\mathrm{FE})$ & 36 \\
Gesture & $(\mathrm{GES})$ & 6 \\
Kinetics (hands or feet movement) & $(\mathrm{K})$ & 35 \\
Posture (movement of torso) & $(\mathrm{P})$ & 45 \\
Verbal - Rising intonation or increasing/ & $(\mathrm{VIP})$ & 4 \\
$\quad$ slowing down voice pitch signalling & & 6 \\
emphasis (VIP) & $(\mathrm{IP})$ & 0 \\
Proxemics (change in distance between & $(\mathrm{DP})$ & \\
interlocutors, while assuming initial & & \\
shot distance as degree zero), divided & & \\
into increased proxemics for minimi- & & \\
zation of distance (IP) and dimin- & & \\
ished proxemics (DP) for increased & & \\
proxemics & &
\end{tabular}


Table 2. Transcript of verbal turns in the 'Hitch' scene, accompanied by a transcript of the concurrent modes.

\begin{tabular}{|c|c|c|c|c|c|c|c|}
\hline \multirow{2}{*}{$\begin{array}{l}\text { Verbal transcript of turns in the conversation (by actor: } \\
\text { Act1, WS, EM) }\end{array}$} & \multicolumn{7}{|c|}{ Mode } \\
\hline & $(\mathrm{FE})$ & (GES) & $(\mathrm{K})$ & $(\mathrm{P})$ & $(\mathrm{VIP})$ & (IP) & (DP) \\
\hline (1) Act1: Hi & & & & $(\mathrm{P})$ & & & \\
\hline $\begin{array}{l}\text { (2) Act1: I noticed your glass was getting a little low, so I took the } \\
\text { liberty of bringing you another Apple Martini. } \\
\text { (3) EM: Thank you }\end{array}$ & & (GES) & $(\mathrm{K})$ & & & & \\
\hline $\begin{array}{l}\text { (4) Act1: And I couldn't help but notice that you look a lot like my } \\
\text { next girlfriend }\end{array}$ & $(\mathrm{FE})$ & & & & & & \\
\hline (5) EM: What's your name? & & & $(\mathrm{K})$ & $(\mathrm{P})$ & & (IP) & \\
\hline (6) Act 1: They call me Chip & $(\mathrm{FE})$ & & & & & & \\
\hline (7) EM: Ahh, you can't get them to stop? & & & & & & & \\
\hline $\begin{array}{l}\text { (9) EM: Listen Chip, I understand the courage it takes to walk } \\
\text { across the room and generate a relationship out of thin air, so } \\
\text { don't take the following personally }\end{array}$ & $(\mathrm{FE})$ & & $(\mathrm{K})$ & & & & \\
\hline (10) Act1: You have fantastic eyes & & & & & (VIP) & & \\
\hline $\begin{array}{l}\text { (11) EM: (smiling) Thanks, try to listen; this is not reflection on } \\
\text { you, I'm just not interested; but thank you for the compliment } \\
\text { and for coming over }\end{array}$ & $(\mathrm{FE})$ & & $(\mathrm{K})$ & & & & \\
\hline (12) Act1: you're welcome; so do you like Cuban food? & & & & $(\mathrm{P})$ & (VIP) & & \\
\hline $\begin{array}{l}\text { (13) EM: Chip, seriously, that was not quote for'I wish you try } \\
\text { harder' }\end{array}$ & $(\mathrm{FE})$ & & $(\mathrm{K})$ & & & & \\
\hline $\begin{array}{l}\text { (14) Act1: Are you always shocked down and afraid that the right } \\
\text { man may make you feel... }\end{array}$ & $(\mathrm{FE})$ & & & $(\mathrm{P})$ & & (IP) & \\
\hline $\begin{array}{l}\text { (15) WS: ... feel like a natural woman? Sorry I'm late honey, I } \\
\text { couldn't get a cub; how was the meeting? }\end{array}$ & $(\mathrm{FE})$ & (GES) & & & & & \\
\hline $\begin{array}{l}\text { (16) EM: Oh wow, there was a beginning, a middle and an end. } \\
\text { Nice to meet you Chip }\end{array}$ & $(\mathrm{FE})$ & & $(\mathrm{K})$ & & & & \\
\hline $\begin{array}{l}\text { (17) Act1: Chip gaping in dismay, standing up and walking away, } \\
\text { uttering:'You too' }\end{array}$ & $(\mathrm{FE})$ & & & $(P)$ & & & \\
\hline $\begin{array}{l}\text { (18) WS: Now, on the one hand, it is very difficult for a man to } \\
\text { even speak to someone who looks like you, but, on the other } \\
\text { hand, should that be your problem? }\end{array}$ & $(\mathrm{FE})$ & & & & & & \\
\hline (19) EM: So life's quite hard all around & (FE) & & $(\mathrm{K})$ & & & & \\
\hline $\begin{array}{l}\text { (20) WS: Not if you pay attention; I mean you're sending off all } \\
\text { the right signals; no earrings, heels under two inches, your hair } \\
\text { is pulled back, you're wearing reading glasses with no book, } \\
\text { drinking a grey goose martini, which means you had a hell of } \\
\text { a week and a beer just wouldn't do it. And if that wasn't clear } \\
\text { enough there's always FUCK OFF stamped on your forehead }\end{array}$ & & & $(\mathrm{K})$ & $(\mathrm{P})$ & & & \\
\hline (21)EM: laughing & $(\mathrm{FE})$ & & $(\mathrm{K})$ & & & & \\
\hline $\begin{array}{l}\text { (22)WS: Because who's gonna believe that there is a man out } \\
\text { there that can sit down beside a woman he doesn't know and } \\
\text { genuinely be interested in who she is, what she does, without } \\
\text { his own agenda? }\end{array}$ & $(\mathrm{FE})$ & $(G E S)$ & $(\mathrm{K})$ & & & & \\
\hline $\begin{array}{l}\text { (23) EM: Yeah, I wouldn't even know what that would look like. } \\
\text { So what would someone like that say? }\end{array}$ & $(\mathrm{FE})$ & (GES) & $(\mathrm{K})$ & & & & \\
\hline $\begin{array}{l}\text { (24) WS: Well, he'd say my name is Alex Hitchins and I am a } \\
\text { consultant, but she probably wouldn't be interested in that } \\
\text { because she'd be counting the seconds until he left }\end{array}$ & & & $(\mathrm{K})$ & $(\mathrm{P})$ & & $(\mathrm{IP})$ & \\
\hline (25) EM: Thinking he was like every other guy & & & $(\mathrm{K})$ & & (VIP) & & \\
\hline $\begin{array}{l}\text { (26) WS: which life experience has taught us is a virtual certainty; } \\
\text { but then he'd ask her name and what she did for a living, and } \\
\text { she might blow him off, or she might say ... }\end{array}$ & $(\mathrm{FE})$ & & $(\mathrm{K})$ & & & & \\
\hline $\begin{array}{l}\text { (27) EM: I'm Sarah Millas and I run the gossip column at the } \\
\text { Standard; and then he'd ask all these penetrating questions } \\
\text { about it because he would be sincerely if atypically interested }\end{array}$ & $(\mathrm{FE})$ & & $(\mathrm{K})$ & $(\mathrm{P})$ & & $(\mathrm{IP})$ & \\
\hline (28) WS: No & (FE) & & $(\mathrm{K})$ & & & & \\
\hline (29) EM: No? & $(\mathrm{FE})$ & & & & & & \\
\hline (30) WS: He'd be interested ... & $(\mathrm{FE})$ & & $(\mathrm{K})$ & & & & \\
\hline (31) EM: Hmmm & $(\mathrm{FE})$ & & (K) & & & & \\
\hline $\begin{array}{l}\text { (32) WS: ... but he'd see that there is no way he could possibly } \\
\text { make her realize that he is for real }\end{array}$ & $(\mathrm{FE})$ & & $(\mathrm{K})$ & & & & \\
\hline
\end{tabular}


Verbal transcript of turns in the conversation (by actor: Act1, WS, EM)

(33) EM: Well, he could be funny and charming and refreshingly original

(34) WS: wouldn't help

(35) EM: don't you hate it when that happens?

(36) WS: Not really, they both probably going to lead the lives they headed toward; my guess is, they'll do just fine

(37) EM: touching glasses (no verbal utterance)

(38) WS: Pleasure to have met you Sarah Milas

(39) EM: nodding, mouth gaping as WS gets up and leaves

(40) Waitress: This Martini from the gentleman who just left

(FE) (GES)

\section{(FE)}

(FE)

(FE)

(FE)

(FE)
Mode

(K)

(K)

(K)

(K)

(K)

(K) $\quad(\mathrm{P})$

analysed scene concerns a flirtatious predicament between Will Smith (designated as WS henceforth) and Eva Mendez (designated as EM henceforth) at a bar. For the sake of noting differences in configurations of flirtatious multimodal signs, I included in the scene the flirtation between Eva Mendez and one of WS's students (henceforth designated as Act1) that directly precedes the flirtatious confrontation between the main heroes. The considered modes in this scene are facial expression, gesture, kinetics, posture, rising intonation or increasing/slowing down voice pitch (as regards the verbal mode) and proxemics (increasing/decreasing) and were used in the coding scheme of multimodal social interactions adopted by Norris (2011). Hence, they are directly relevant in mapping multimodal interaction patterns among social actors. 'Multimodal interaction analysis takes the action as its unit of analysis. An action is a social actor acting with or through a mediational means or cultural tool' (Norris 2011, 279). The coding scheme was deliberately chosen at such an abstraction level, that is without further qualifications into sub-types (e.g. whether facial expressions concern ears, lips, eyebrows, nose, etc.) due to space limitations and for the sake of parsimony. However, such nuanced modal occurrences were noted in the notes to each transcribed multimodal conversational turn and will be further analysed in the ensuing discussion. The scene was segmented into 40 conversational turns (Table 2 ) using the professional video editing program Sony Vegas, while assuming the verbal mode as the dominant one in the interaction, with the exception of two turns that were marked by the absence of any verbal component. Hence, the scene was not segmented, as is often the case in filmic analysis, into frames or sequences as minimal units of analysis (cf. Bateman and Schmidt 2012; Rossolatos 2014), but primarily into verbal conversational turns, the reason being that what we are interested in exploring is the incidence of other than verbal modes concurrently with speech in a flirtatious conversation and how they function with regard to speech, that is, eminently, either as complementary (by adding emphasis), or as contrary (by negating) or as supplementary in any other way to the manifest speech content. As will be shown, in fact, multimodal signs in flirtatious interactions constitute a sort of sub-script that runs in parallel to speech and that abides by a tacit grammar (discernible by virtue of recurrent multimodal signs in tandem with specific functions they perform vis-à-vis manifest speech) which may be called the grammar of seduction and which is mostly characterized by the (seductively semantic) operations of postponement and reversal that work in tandem with manifest speech, in one of the aforementioned three manners. Pursuant to these preliminary methodological considerations, here below follows a discussion of the most important findings from this analysis.

In total, 72 incidences of modes other than verbal were noted throughout the conversational turns in this scene, concurrently with speech, with an average of two modes per turn. The hierarchical ordering of modes in the selected corpus is displayed in Table 1. In greater detail, the majority of noted kinetic sub-types consist of movements of hands and head, while facial expressions display a greater variety, albeit more invariably so by actor, viz. lifting eyebrows being indicative of WS's facial expressions, smiling being indicative of EM's and converging eyebrows being indicative of Act1's. Change of posture consist mostly of leaning forward with view to adding emphasis to the verbal content of the interaction, with the exception of torso movements that are attributable to entering and/or leaving from the scene. Gaze 
is relatively fixed throughout the dialogue, and wherever turns in the direction of gazing were noted, albeit scarce, they were coded as shifts in facial expression for the sake of parsimony. Gestures were quite variable, ranging from crossing to stretching hands, largely with view to emphasize the contents of speech, while voice pitch speeded up and/or slowed down, again for the sake of emphasis. Proxemics are relatively fixed throughout the scene, given that the actors are seated facing each other, with the exception of leaning forward on rare occasions with view to emphasize the importance of their utterance.

Pursuant to the display of these preliminary findings concerning how different modes occurred in the concerned scene and their role with regard to the verbal interaction that is evidently the dominant mode in the conversation between the involved actors, let us proceed with examining, firstly, if there are configuration modal patterns that carry implications for the seductive discourse that is deployed by the two male actors, and if yes, whether there are differences between the two actors' approaches. Secondly, we shall examine how the female actor's modal configurations vary in her interaction with each of the male actors and whether there are instances where other than verbal modes override the meaning that is communicated in manifest speech. These will be considered alongside the prevalent themes of radical uncertainty, reversal and postponement, as dominant operations responsible for shaping the cultural field of flirtation.

With regard to the first dimension, we notice two dominant modal configurations that differentiate the male actors. Act 1 seeks to confirm his domineering role over the female actor whom he approaches as a trophee to be conquered through the modal configuration of accentuated proxemics (leaning forward) and sitting at a higher level than EM (suggesting a relationship of dominance)/converging eyebrows (emphasizing his intentions in a scaringly austere fashion)/ raising the tone of his voice (again, in the context of his wider domineering posture). In the face of this conquering intentionality, EM communicates in her manifest speech constantly a wish for ending this conversation, thus symbolically castrating her interlocutor, albeit in a non-feigned manner since she is very explicit about it. Her intention is further supported by a multimodal configuration of limited postural shifts and very controlled kinesics, demonstrating that her decision is irrevocable, both verbally and paralinguistically. This becomes more evident if we compare her wider paralinguistic posture with her interaction with WS, in which case she is much more relaxed, with less controlled and more spontaneous kinesics and facial expressions that are indicative of enhanced openness and less rigid controls. In her interaction with ACT 1, EM does not flirt, she just wants him out of the picture: there is no undecidability in the employed signs since both verbal and non-verbal modes are in perfect alignment alongside a clear 'no go' decision; there is a constant reversal, but not the kind of reversal that is definitive of the play of seduction, save for the castrating reversal that undercuts the domineering attitude of a wannabe seducer; there is no postponement that might allow for glimpsing a probability of success, save for a repetition of a wish for closure that is manifestly expressed repeatedly by EM. This scenario changes radically and rapidly in the interaction with WS. WS does not seek to dominate over EM, but (i) to affirm that he 'cannot win' over the principle of constant reversibility (see Table 2, utterances (32), (34)), by capitalizing on postponing manifesting his intentions directly, as against Act1. Whereas Act1 kicked off his conversation with EM by committing the greatest of all blunders, according to the principles of seduction, that is by assimilating EM to his'new girlfriend', WS kicks off his part, and keeps highlighting as the interaction deploys, that he is flirting with the improbable (i.e. the least certain), while keeping postponing his intentions. In terms of modal configuration, his kinesics are less austere, he raises his eyebrows, thus affirming paralinguistically that his discourse is aporetic (leading nowhere). The way he manages to extract pertinent information from EM is by reducing the conversation to an impersonal, typical dialogue based on trite cultural expectancies. In short, he is reversing any rule-bound conceptualization of the playful discourse of seduction for the sake of luring (that is seducing) EM into agreement with what he knows, that is the secret of seduction as improbability and constant reversal. And this is the only thing that can be affirmed, absolute non-positivity and its attitudinal counterpart of radical uncertainty, as attested by EM's purely non-verbal closing turn: head nodding; mouth gaping. The multimodal subscript, as silent complicity of signs, affirms her interest by virtue of having undercut manifestly (in speech) the probability of achieving the telos of seduction. 


\subsection{Allo-telic vs, auto-telic signs}

The above illustrated radical uncertainty is tantamount to the castration of the speaking subject that is in principle divested of the symbolic phallus that allows for the appearance in discourse of determinate signifiers whereupon the telos may cling, like small islands in a vast sea of uncertainty. This remark also reveals the need for a fundamental reorientation of the relationship between signifier and signified, by introducing a distinction between static vs. processual signs.

Static signs designate a relationship between a signifier and a signified as a snapshot of the relationship between sound (or other mode) and its concept, sedimented and dislocated from a dynamic of a seductive communicative context. Static signs are auto-telic, i.e. their meaning is inherent in the equation as snapshot. Processual signs, on the contrary, designate signifiers whose meaning is postponed and, hence, which do not signify until the chain that links them will have been fully deployed. Processual signs are allo-telic, that is their meaning resides in the final interpretant (in Peirce's terms) or archi-signified that conditioned their deployment in the first place, but which, at the same time, thwarted them from being amenable to signifying correlations as snapshots. The signs of seduction are processual and allo-telic, they are driven by desire, yet postpone desire in the process (and potentially do not even allow its fulfilment) and, hence, they are auto-telic at the same time. They are not bound up with universal signifieds, but with ephemeral, interchangeable, blurred and occasionally affective ones, always in suspense and non-closure, by definition not amenable to totalization. Moreover, they do not constitute en masse a stable and diachronic exchange currency. The incidence of such recurrent semiotic multimodal constellations or 'arbitrary constellations' (Baudrillard 1990, 146) in elliptical conversational interactions between flirting social actors points only hazily to a case of 'punchlines'; more likely, we are concerned with sedimented fragments of a floating discourse of desire. They are provisional entrapments of meaning ('the seductress turns desire itself into an illusion or trap' Baudrillard 1990, 85), inasmuch as Nietzsche assimilated women's ornaments with 'trappings of power'. In our case, these trappings translate into visible (phallic) simulacra of an allo-telic process that exceeds phallic simulacra as telos and master-signified, while, at the same time, allowing for the sliding of the master signified in the postponement movement which runs in parallel to the promise of desire's fulfilment. The allo-telic process of seduction is a double movement of postponement and fulfilment in its deployment, the promise of an epiphenomenal reality, inasmuch as the undercutting (castration) of the phallic order that fuels sexual desire.

Only ironically, ornaments and kinetic signs that are part and parcel of a seductive semiotic economy may be tagged as 'sexy'. In fact, they are, at the same time, sexy and asexual, partaking of the double movement of allo-telic desire and auto-telic simulation. Subsequently, a judgement of taste (e.g. sexy) that 'refers' to a thong, for example, is by definition ironic, as it, ultimately, refers to the loss of signification as refraction in simulation's hall of mirrors or as the echo of the taste utterance in an open field of postponement and loss ('each sign is tied to others, not within the abstract structure of language, but within the senseless unfolding of a ceremonial; they echo each other and reduplicate themselves in other, equally arbitrary signs' [Baudrillard 1990, 137]).

An ornament or two in the panoply of seduction is nothing but a performative attestation of desire's flight (postponement) in the face of seduction. The more auto-telic semiotic multimodal constellations proliferate in a flirting field, the less sex is likely to consummate as their allo-telic horizon. But the utopian fantasy of a meticulous micro-engineering of the process of seduction is what fuels the proliferating emergence of professional dating and flirting consultation services. The same holds for the augmenting popular press literature (e.g. Men's Health, Cosmopolitan) on 'how to'tips (cf. supra on the know-how of the habitus) regarding seduction tactics. This cultural predicament is tantamount to what Baudrillard conceived in Seduction as 'obscenity', akin to pornography's obsession with extreme close-ups or the encapsulation of the labour of sex in an infinite series of snapshots that aim at usurping seduction's power. This discursive accumulation is, thus, not equivalent to a naïve 'decoding' of seduction's 'secret', but a failure to realize that the secret of seduction is the non-totalizable, non-cumulative and constantly metastatic 'superficial abyss of its own appearance' (Baudrillard 1990, 54). 


\section{Conclusion}

Hopefully, the analytical avenue that was pursued in this paper affords to elucidate why the cultural field of flirtation and seduction as its discursive adjunct constitutes a peculiar case of non-habitus. The emphasis that was laid on the semiotic economy that undergirds signs' constant reversibility and potential loss in the process of seduction aimed at accounting for an indispensable missing link in our understanding of the not necessarily allo-telic and instrumentalist field of flirtation.

In lieu of an answer to the key question that hovered over the text as its (be)heading, that is 'Before the consummation what?', what emerges from the preceding analysis is that before the consummation comes postponement and dissemination as consummation's moments which threaten the very likelihood of consummation. In fact, the proliferating multimodal semiotic constellations that might be shown to be accumulating across the aleatoric trajectory of seductive discourse turned out to be overdetermining as regards the event of consummation. As if by a sudden turn of the cards, this eventuality is reversibly re-inscribed in the play of seduction as its moment.

If, indeed, we are confronted with a non-habitus and with an 'aimless' practice, then the semiotic capital that is required of flirting subjects as tactical toolbox, orientation strategy(-ies) and disposition (vertigo), constitutes a form of radical indebtedness and liability.

\section{Notes}

1. For a focused study on the erotic habitus, see Green (2008).

2. 'Bourdieu lists as the main forms of capital symbolic capital (i.e. status); social capital (i.e. useful contacts and networks); cultural capital (e.g. educational qualifications)' (Crossley 2001, 87). 'To speak of specific capital is to say what capital is worth in relation to a specific field, within the limits of this field, and that it is convertible into another species of capital under certain conditions' (Savage and Silva 2013, 113).

3. Also see Vaughan (2010) for more filmic examples in terms of film aesthetics and narrative structure (Once Upon a Time in the West, Vertigo) and McQueen (2013; with regard to Crash).

4. Despite his earlier repudiation of especially Lacanian psychoanalysis (a scientific attitude that was reversed during the last decade of his life), there are striking similarities between central concepts in Bourdieu's sociological theory and Lacanian psychoanalysis, but also considerable influences from Freudian psychoanalysis, with the common orientation between symbolic power and Lacan's Symbolic Order ranking prominently among them (see Steinmetz 2006 for a thorough analysis of parallels between Bourdieuian sociology and psychoanalytic concepts).

5. The scene may be accessed at https://www.youtube.com/watch?v=wyT5UHDi4a0. It lasts, in total, for $3 \mathrm{~min}$ and $10 \mathrm{~s}$.

\section{Acknowledgements}

I would like to thank the anonymous reviewers of Continuum for their stimulating comments.

\section{Disclosure statement}

No potential conflict of interest was reported by the author.

\section{Notes on contributors}

George Rossolatos (MSc, MBA, PhD) is an academic researcher, marketing practitioner and the editor of the International Journal of Marketing Semiotics (Department of English, Kassel University, Germany). Major publications include the Handbook of Brand Semiotics (2015; ed. and co-author), Semiotics of Popular Culture (2015), Brand Equity Planning with Structuralist Rhetorical Semiotics (2012, 2014), //rhetor.dixit//: Understanding ad texts' rhetorical structure for differential figurative advantage (2013), Applying Structuralist Semiotics to Brand Image Research (2012), Interactive Advertising: Dynamic Communication in the Information Age (2002; ed. and co-author), plus numerous articles in trade and academic journals. His research interests focus on new media and cultural studies, interpretivist consumer research, branding/ advertising and span various disciplines such as rhetoric, semiotics, phenomenology, deconstruction, psychoanalysis, communication theory. 


\section{References}

Bateman, John A., and Karl-Heinrich Schmidt. 2012. Multimodal Film Analysis. London: Routledge.

Baudrillard, Jean. 1990. Seduction. Montreal: Culture Text Series.

Beer, David. 2013. "Genre, Boundary Drawing and the Classificatory Imagination." Journal of Cultural Sociology 7 (2): $156-160$.

Bottero, Wendy, and Nick Crossley. 2011. "Worlds, Fields and Networks: Becker, Bourdieu and the Structures of Social Relations." Journal of Cultural Sociology 5 (1): 99-119.

Bourdieu, Pierre. 1985. "The Social Space and the Genesis of Groups." Theory \& Society 14 (6): 723-744.

Bourdieu, Pierre. 1991. Language and Symbolic Power. Oxford: Polity.

Bourdieu, Pierre. 1993. The Field of Cultural Production. New York: Columbia University Press.

Bouveresse, Jacques. 1999. "Rules, Dispositions and the Habitus." In Bourdieu: A Critical Reader, edited by Richard Shusterman, 45-63. Oxford: Blackwell.

Bühlmann, Felix, Thomas David, and André Mach. 2013. "Cosmopolitan Capital and the Internationalization of the Field of Business Elites: Evidence from the Swiss Case." Journal of Cultural Sociology 7 (2): 211-229.

Butler, Judith. 1999. "Performativity's Social Magic." In Bourdieu: A Critical Reader, edited by Richard Shusterman, 113-128. Oxford: Blackwell.

Crossley, Nick. 2001. "The Phenomenological Habitus and Its Construction." Theory and Society 30: 81-120.

Deighton, John, and Kent Grayson. 1995. "Marketing and Seduction: Building Exchange Relationships by Managing Social Consensus." Journal of Consumer Research 21 (4): 660-676.

Elafros, Athena. 2012. "Locating the DJ: Black Popular Music, Location and Fields of Cultural Production." Journal of Cultural Sociology 7 (4): 463-478.

Fantasia, Rick. 2010. "'Cooking the Books' of the French Gastronomic Field." In Cultural Analysis and Bourdieu's Legacy: Settling Accounts and Developing Alternatives, edited by Elizabeth Silva and Alan Warde, 29-44. London: Routledge.

Friedman, Sam, and Giselinde Kuipers. 2013. "The Divisive Power of Humour: Comedy, Taste and Symbolic Boundaries." Journal of Cultural Sociology 7 (2): 179-195.

Fowler, Bridget. 1997. Pierre Bourdieu and Cultural Theory: Critical Investigations. London: Sage.

Green, Adam I. 2008. "The Social Organization of Desire: The Sexual Fields Approach." Sociological Theory 26 (1): 25-50.

Grenfell, Michael. 2010. "Working with Habitus and Field:The Logic of Bourdieu's Practice." In Cultural Analysis and Bourdieu's Legacy: Settling Accounts and Developing Alternatives, edited by Elizabeth Silva and Alan Warde, 14-27. London: Routledge.

Mander, Mary S. 1987. "Bourdieu, the Sociology of Culture and Cultural Studies." European Journal of Communication 2: 427-453.

Martin, John L. 2003. “What is Field Theory?" American Journal of Sociology 109 (1): 1-49.

McQueen, Sean. 2013. "Seducing-machines: Baudrillard, Deleuze, and Crash." International Journal of Baudrillard Studies 10 (1). http://www.ubishops.ca/baudrillardstudies/vol-10_1/v10-1-mcqueen.html.

Norris, Sigrid. 2011. Identity in (Inter)action: Introducing Multimodal (Inter)action Analysis. Berlin: De Gruyter.

Rossolatos, George. 2014. "Conducting Multimodal Rhetorical Analysis of TV Ads with Atlas.Ti 7." Multimodal Communication 3 (1): 51-84.

Rossolatos, George. 2015. Semiotics of Popular Culture. Kassel: Kassel University Press.

Savage, Mike, and Elizabeth B. Silva. 2013. "Field Analysis in Cultural Sociology." Journal of Cultural Sociology 7 (2): 161-178. Searle, John. 1979. Expression and Meaning: Studies in the Theory of Speech Acts. Cambridge: Cambridge University Press.

Simmel, Georg. 1984. On Women, Sexuality and Love. New Haven, CT: Yale.

Steinmetz, George. 2006. "Bourdieu's Disavowal of Lacan: Psychoanalytic Theory and the Concepts of "Habitus" and "Symbolic Capital'"'.' Constellations 13 (4): 445-464.

Swartz, David L. 1997. Culture \& Power: The Sociology of Pierre Bourdieu. Chicago, IL: University of Chicago Press.

Swartz, David L. 2003. "In Memoriam Pierre Bourdieu (1930-2002): Drawing Inspiration from Bourdieu's Sociology of Symbolic Power." Theory and Society Special Issue on the Sociology of Symbolic Power: A Special Issue in Memory of Pierre Bourdieu 32 (5/6): 519-528.

Tavory, Iddo. 2010. "The Structure of Flirtation: On the Construction of Interactional Ambiguity." In Studies in Symbolic Interaction Vol. 33, edited by Norman Denzin, 59-74. Bingley: Emerald.

Taylor, Charles. 1999. "To Follow a Rule ...." In Bourdieu: A Critical Reader, edited by Richard Shusterman, 29-44. Oxford: Blackwell.

Vannini, Philip, and Aaron M. McRight. 2004. "To Die for: The Semiotic Seductive Power of the Tanned Body." Symbolic Interaction 27 (3): 309-332.

Vaughan, Hunter M. 2010. “The Paradox of Film: An Industry of Sex, a Form of Seduction (on Jean Baudrillard's Seduction and the Cinema)." Film-Philosophy 14 (2): 41-61.

Whitty, Monica T. 2004. "Cyber-flirting: An Examination of Men's and Women's Flirting Behaviour Both Offline and on the Internet." Behaviour Change 21 (2): 115-126. 
Williams, Alex. 2013. "The End of Courtship?" New York times, January 11. http://www.nytimes.com/2013/01/13/fashion/ the-end-of-courtship.html?_r=0.

Wohl, Hannah 2014. Communities of Sense: Maintaining 'Good Taste' in an Erotic Arts Club. Working paper, Center for Cultural Sociology, Yale University. ccs.research.yale.edu/documents/public/CCS_WP/WP5_WOHL.pdf.

Yates, Candida. 2010. "Spinning, Spooning and the Seductions of Flirtatious Masculinity in Contemporary Politics." Subjectivity 3 (3): 282-302. 